paired-associate performance across a variety of materials to see if there were genuine individual differences in paired-associate learning comparable to those observed in free recall (cf. Gorfein, Blair, \& Rowland, 1968; Gorfein \& Blair, in press).

Since the four measures of interference correlate insignificantly with each other, we have used all four measures in attempts to see their relationship to the serial-position curve of free recall. Correlations involving the two measures of retroactive inhibition, the savings on the relearning of List 1 and the first trial of releaming List 1 and the four free-recall measures, are all statistically insignificant, having an absolute value ranging between .02 and .31 . Those involving the two proactive-inhibition measures based on List 3 relearning performance are statistically insignificant, with a single exception: a negative correlation of -.39 between savings on 3 and primacy. An explanation of this unexpected finding is suggested by examining the relationship of the learning of List 3 to the performance in free recall, as well as the relationship of the learning of List 3 and the savings on relearning. As shown in Table 1, primacy in a learning of a third paired-associate list correlate .40 . The obtained correlation between the savings score in List 3 and the learning of List 3 is -.66 If we, therefore, partial out the ability to learn from the correlations between the savings measure and primacy, we find a partial correlation of -18 , which is statistically insignificant. It is our belief, therefore, that the observed negative correlation between the savings score and primacy is due to the large ability-to-learn component reflected in the savings measure.

In general, we have demonstrated a relationship between paired-associate performance and performance in free recall. Most significant is the indication that an analysis of the free-recall situation, in terms of the serial-position curve, yields a set of relationships that could have been glossed over if such a gross measure as total free recall had been employed.

\section{REFERENCES}

DEESE, J. E., \& HULSE, S. H. The psychology of leaming. (3rd ed.) New York: McGraw-Hill, 1967.

EARHARD, M. Subjective organization and list organization as determinants of free recall and serial recall memorization. Joumal of Verbal Learning \& Verbal Behavior, 1967, 6, 501-507.

EARHARD, M., \& ENDICOTT, O. Why are there individual differences in subjective organization during frec-recall memorization? Journal of Verbal Learning \& Verbal Behavior, 1969, 8, 316-319.

GORFEIN, D. S., \& BENNETT, R. W. Analy sis of free-recall over multiple trials. Paper presented at the annual meeting of the Psychonomic Society, 1967.

GORFEIN, D. S., BENNETT, R. W., ARBAK, C.,
\& GRAVES, D. Individual differences in the serial position curve of free-recall. Journal of Verbal Leaming 4 Verbal Behwior, in press.

GORFEIN, D. S, \& BLAIR, C. Fsctors affecting multiple-trial free-recall. Joumal of Educational Psychology, in press.

GORFEIN, D. S., BLAIR, C., \& ROWLAND, C. The generality of free-recall: II. Performance as a function of type of materinl Psychonomic Science, 1968, 13, 111-112.

MELTON, A. W. (Ed.), Categories of human learning. New York: A cademic Press, 1964.

NOBLE, C. E. Measurement of associntion value (a), rated associations (an) and scaled meaningfubess $\left(\mathrm{m}^{\prime}\right)$ for the $2100 \mathrm{CVC}$ combinations of the English alphabet. Psychological Reports, 1961, 8, 487-521.

RYAN, S. D., \& WHMBEY, A. E.STM abilities in LTM tasks. Psychonomic Science, 1968, 10, 297-298.

THORNDIKE, E. L., \& LORGE, I. The teacher's word book of 30,000 words. New York: Bureau of Publications, Teachers College, Cohumbia Untversity, 1944.

UNDERWOOD, B. J. The representativeness of rote verbsl learning. In A. W. Melton (Ed.), Categories of human leaming. New York: Academic Press, 1964.

WHIMBEY, A. E, \& LEIBLUM, S. L. Individual differences in memory span with and without activity intervening between presentation and recall. Journal of Educational Psychology, $1967,5,311-314$.

\section{NOTES}

1. The research reported was done under the supervision of the senior athor and fulfills an independent study requirement of the two junior authors.

2. Written at the Human Performance Center, University of Michigan. We gratefully acknowledge the support of Dr. Arthur W. Melton in the preparation of this report.

3. For $\mathrm{p}>.325, \mathrm{p}<.05$; for $\mathrm{r}>.418, \mathrm{p}<.01$.

\title{
The intuitive estimation of means with auditory
}

presentation

\author{
G. LOWE, University of Hull, Hull, \\ England
}

Subjects were required to make intuitive estimates of the means of samples of 10 or 20 numbers with auditony presentation. As in previous experiments, performance was fairly accurate, and increased sample size and variance resulted in overestimation. Accuracy was also affected by the value of actual means and there were significant interactions between sample size and variance and between sample size and actual mean. The observed tendency for intuitive estimates to be more accurate with auditory than with visual presentation was thought to be a feature of sequential processing strategies.

A previous investigation (Bulger, Hiles, \& Lowe, 1969), along with earlier studies, found that Ss' performance as intuitive descriptive statisticians was quite accurate, although error scores increased with sample size and information-processing rate. It was suggested that the increased sample size might necessitate the use of different strategies (possibly in the form of sequential, as opposed to simultaneous, processing). Most studies of the intuitive estimation of means have, in fact, used visual presentation of the data (number samples or anays), which permits the use of either sequential (successive scanning) or simultaneous (parallel) processing strategies, or, indeed, some mixture of the two. Auditory presentation is, of course, restricted to sequential inputs, and, in this case, Ss will presumably adopt a sequential strategy of information processing to arrive at an estimate of the mean of a sample of numbers. The aim of the present investigation was to determine the accuracy and the characteristics of $\mathrm{Ss}^{3}$ estimation performance under such conditions.

\section{APPARATUS}

Numbers (integers) ranging between 0 and 20 in random order were recorded on magnetic tape for presentation by tape recorder. Lists (or samples) consisted of either 10 or 20 numbers, and distributions were symmetrical. There were 14 different combinations of means and variances for each sample size. The 7 sample means were $4,5,6,7,8,9$, and 10 , each with constant variance equal to 6.4 ; the 7 sample variances were $6,11,18,27,36,51$, and 66 , each with constant mean equal to 10 . There were, thus, 28 different types of number samples. Each of these was presented in four different random arrangements, making 112 different presentations altogether.

\section{PROCEDURE}

The Ss were told that they would be presented with lists or samples of numbers, and that they had to estimate the mean of each sample. They were given a preliminary practice session of 20 presentations, none of which were included in the main 


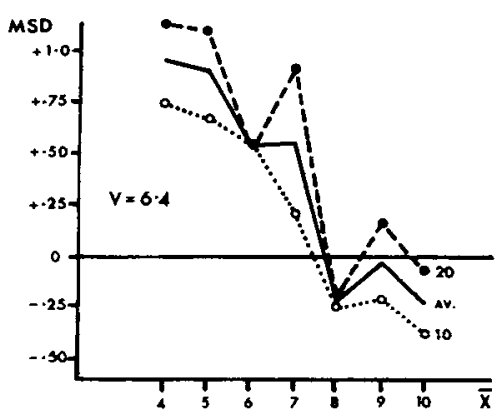

Fig. 1. Mean signed deviation (MSD) of Ss' estimates of the mean as a function of sample mean and sample size.

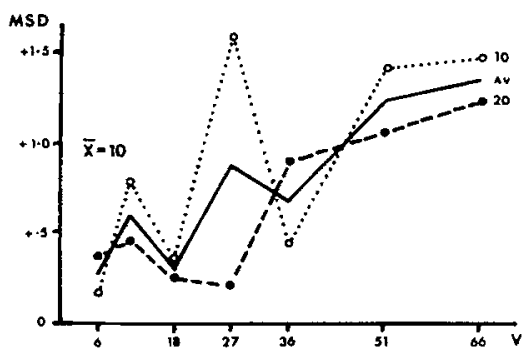

Fig. 2. Mean signed deviation (MSD) of Ss' estimates of the mean as a function of sample variance and sample size.

experimental session, but which nevertheless were representative of the main series.

Each of the 112 lists was given once in randomly arranged order of presentation. The auditory-presentation rate was fixed at 10 numbers per $4 \mathrm{sec}$ and 20 numbers per $8 \mathrm{sec}$, with $5 \mathrm{sec}$ between trials for Ss to record their mean estimations on response sheets. In addition, there were 2 -min rest pauses after blocks of 14 trials.

$$
\text { SUBJECTS }
$$

A group of 24 undergraduate students in the Psychology Department participated in this experiment. They were generally familiar with the concept of "mean," but had not been previously involved in intuitive statistical tasks of this sort. Ss were seated in a small lecture room with the tape recorder positioned in front of them. None of the Ss reported any difficulty in hearing the auditory presentation of numbers.

\section{ANALYSIS OF DATA}

Error scores of Ss' estimates were expressed in terms of mean signed deviation (MSD) of the estimates from the actual sample means.

\section{RESULTS}

Overall, performance was fairly accurate, with an average MSD of +.38 . Figure 1 shows the effects of sample mean and sample size on Ss' estimations. Sample mean significantly affected intuitive estimation $(F=24.75, d f=6 / 138$, $\mathrm{p}<.001$ ), in that lower actual means were overestimated and higher ones slightly underestimated. Ss' estimates were also significantly affected by sample size $(F=17.34, \mathrm{df}=1 / 138, \mathrm{p}<.001)$. Samples of 20 led to overestimation of means, but, with higher actual means, this resulted in more accurate performance because of the tendency to underestimate with samples of 10. This interaction.was significant $(F=2.49$, df $=6 / 138, p<.025)$.

Figure 2 shows the effects of sample variance and sample size. Intuitive estimation performance was again generally quite good, although rather less accurate overall than that when sample variance was constant. In these samples, the actual mean $(\bar{X}=10)$ was consistently overestimated, and the degree of overestimation increased with sample variance $(F=5.21, d f=6 / 138$, $\mathrm{p}<.001)$. Sample size was not a significant factor, however, in relation to error scores $(\mathrm{F}=1.64, \mathrm{df}=1 / 138, \mathrm{p}>.10)$, although there was a significant interaction between sample size and variance $(F=2.84$, df $=6 / 138, p<.025)$.

\section{DISCUSSION}

The general accuracy of Ss' intuitive estimates of the means is consistent with previous findings and with the notion that man is an efficient intuitive descriptive statistician (Peterson \& Beach, 1967). Further support for this comes from the observation that Ss' estimates were affected by the same variables as those affecting formal statistical procedures.

With regard to the auditory presentation of data, it is of interest to note that performance under these conditions seemed to be better than that under visual-presentation conditions with similar number samples. This may suggest that sequential-processing strategies, presumably necessitated by auditory presentation, are more efficient than simultaneous or other processing strategies in making intuitive statistical judgments of this kind.

\section{REFERENCES}

BULGER, P. M. J., HILES, D. R., \& LOWE, G. Presentation time and the intuitive estimation of means. Psychonomic Science, 1969, 15, 191-192.

PETERSON, C. R., \& BEACH, L. R. Man as an intuitive statistician. Psychological Bulletin. $1967,68,29-46$. 